\title{
Buildings behaving badly: a behavioral experiment on how different motivational frames influence residential energy label adoption in the Netherlands
}

\author{
Jillian Student $^{1} \cdot$ Elissaios Papyrakis $^{2,3} \cdot$ Pieter van Beukering $^{4}$
}

Received: 4 November 2014 / Accepted: 15 January 2016/Published online: 1 February 2016

(C) The Author(s) 2016. This article is published with open access at Springerlink.com

\begin{abstract}
Heating buildings contributes to approximately $36 \%$ of Europe's energy demand and several EU member states have adopted mandatory energy labels to improve energy efficiency by promoting home weatherization investments. This paper focuses on the perception of the energy label for residential buildings in the Netherlands and the role of different frames (egoistic, biospheric and social norms and neutral frames) in motivating adoption of energy labels for housing. We used a behavioral email experiment and an online survey to investigate these motivational factors. We find that biospheric frames are weaker than the other three motivational frames in terms of engaging interest in the energy label, but that the biospheric frame results in higher willingness to pay (WTP) for the energy label. We also find that age (rather than income) correlates with higher WTP for home energy labels.
\end{abstract}

Keywords Building energy efficiency - Energy conservation - Energy efficiency · (Residential) energy label · Motivating conservation behavior - Motivational (message) framing - Social norms · The Netherlands

\section{Introduction}

While attention to both global and local environmental problems has been increasing, peoples' actions do not always reflect these improvements in environmental awareness and per capita energy consumption is still on the rise (Steg 2008). In Europe, heating buildings

Jillian Student

jillian.student@wur.nl

1 Environmental Policy and Environmental Systems Analysis Groups, Wageningen University, Droevendaalsesteeg 4, 6708 PB Wageningen, The Netherlands

2 International Institute of Social Studies (ISS), Erasmus University Rotterdam, Kortenaerkade 12, 2518 AX The Hague, The Netherlands

3 School of International Development, University of East Anglia, Norwich NR4 7TJ, UK

4 Institute for Environmental Studies, Vrije Universiteit Amsterdam, De Boelelaan 1087, 1081 HV Amsterdam, The Netherlands 
is the source of $36 \%$ of $\mathrm{CO}_{2}$ emissions (Agentschap NL, 2011). Heating and cooling buildings contribute to two major environmental problems, i.e. resource depletion and climate change. Energy conservation is a critical component of the EU's plan to curtail emissions (by at least $20 \%$ by 2020 compared to 1990 levels, see Agentschap NL, 2011; Europa 2015). Residential buildings are especially relevant for saving energy in Europe since $60 \%$ of the estimated energy savings potential for buildings comes from private homes (IDEAL EPBD 2011).

Promoting conservation through energy efficient buildings is an obvious way of addressing this issue. However, many individuals do not know how efficient their building is and what they can do to maximize their home's conservation potential. Energy labels are an important information/market instrument that can help promote awareness on the current level of buildings' energy efficiency, indicate ways to improve efficiency and create explicit value for energy savings (Banerjee and Solomon 2003; Truffer et al. 2001). The residential energy label program is similar to that of energy labels for appliances (e.g. washing machines and refrigerators). The label gives a score between $\mathrm{A}(++)$ and $\mathrm{G}(\mathrm{A}++$ meaning a highly energy-efficient home and $\mathrm{G}$ a highly inefficient home). Unlike the appliance energy label, the residential label also provides information on how to improve energy efficiency and thereby the label score (e.g. conservation behaviors such as insulating a house). The goal of the program is twofold: (1) provide information on the building's current energy efficiency and (2) suggest potential measures to improve efficiency and promote energy conservation. Residents benefit by having better insight into their homes' energy efficiency and what they can do about improving it. Improved efficiency can enhance their comfort level and reduce their spending on energy. Also, as awareness of energy efficiency and energy costs increase, a better label can improve the property's market value as well as provide buyers and renters a better indication of how efficient the building is (Brounen and Kok 2011a, b).

New knowledge (e.g. in the form of energy labeling) can help change attitudes, promote energy savings and influence consumers' demand for housing by considering such information (Steg and Vlek 2009; Stern et al. 1987; Abrahamse et al. 2007). However, new knowledge does not always ensure behavioral changes in terms of energy conservation (Abrahamse et al. 2007). People tend to be reluctant to adjust their behavior when sacrifices are needed (e.g. initial monetary/inconvenience costs). Furthermore, consumers may not be able to accurately assess the short-term investment costs and discomfort against the long-term benefits (Griskevicius et al. 2010; Steg 2008).

The energy label for residential buildings is not widely used in practice although consumers could benefit from more energy efficient homes. Sixty-five percent of Dutch homes were built before 1980 and these buildings are $50 \%$ less efficient than homes built in the last 10 years (Brounen et al. 2012). Furthermore, approximately $5 \%$ of the Dutch household budget is spent on heating and electricity (CBS 2009). In 2009, average costs per household for gas (heating) ranged from $€ 1200$ to $€ 2800$ annually depending on the level of heating efficiency (Brounen and Kok 2011a; Brounen et al. 2012). The Netherlands pays the fourth highest amount for gas (heating) per $\mathrm{kWh}$ in Europe (EEP 2013). Moreover, lower income households budget a proportionally higher part of their income for energy costs (CBS 2009; Brounen and Kok 2011a). Nonetheless, the energy label has met considerable resistance and lack of interest in the Netherlands.

The opposition to the label in the Netherlands is attributed to unclear and lenient policy, negative media attention and distrust (Brounen and Kok 2011a). First, the label was officially voluntary until January 1, 2013. Lack of incentives for adopting a label and absence of label enforcement meant consumers could and still can easily avoid getting the 
label (Murphy and Meijer 2011). Second, unclear policy goals and unsatisfactory implementation led to critical reports from several real estate experts (e.g. the Dutch Association of Realtors, the Homeowners Association and the Renters Association) (Brounen and Kok 2011a). For example, the methodology of calculating the score was not standardized, leading to different label ratings for the same house. The consumer advocacy TV program, Radar, investigated and exposed these problems (see Radar 2007, 2008). The industry's lack of support coupled with negative media attention contributed to lowering consumer confidence in the label; the decreasing label adoption rate (while in $200825 \%$ of houses sold had a label, this fell to $15 \%$ after the airing of Radar) demonstrates some distrust in the energy label (Brounen and Kok 2011a).

Since January 2015, some changes have been made to the residential energy label program. All houses receive a provisional label based on the year it was built, the surface area and building type. However, as with the old system, the label is mandatory only when selling or renting houses and is valid for 10 years. Failing to provide the label entails the risk of being fined up to $€ 405$ (Rijksoverheid 2015). However, people have the opportunity to get the label up until the last minute to avoid the fine, which limits potential buyers' and renters' access to information. To get the definite label, individuals fill in an online form, which is remotely assessed by professionals (Rijksoverheid 2015). No one comes to inspect the house, which can affect the label's credibility as information can be intentionally or unintentionally misrepresented or inaccurate. Majcen et al. (2013a) conclude that thorough in-person inspections are needed if the label is to correctly represent residential buildings' energy efficiency; moreover, accurate calculations are difficult to obtain when inspection is not conducted in a thorough manner. For example, even slight changes in insulation estimates (U-value) result in very different demand levels and energy label calculations. The current changes to the energy label program do not incorporate these insights.

Past research has assessed the role of the energy label as a tool for conservation. Murphy and Meijer (2011) and Murphy et al. (2012) analyzed the energy label in the Netherlands; their findings suggest that the label has failed to reach the policy measure's target group and resulted in minimal emissions reductions. Majcen et al.'s (2013a, b) research suggests the energy label score can predict gas consumption to a degree, but that theoretical estimates of energy use in terms of the energy label are not indicative enough and actual energy consumption averages at each label level should be used instead; moreover, the finding that a good label does not necessarily mean lower energy consumption reflects the findings of similar studies (e.g. Backhaus et al. 2011). On a more positive note, Brounen and Kok (2011a, b) utilized information from real estate and energy label databases to show that homes with a good label ( $\mathrm{C}$ or higher) have a shorter selling time (on average 24 days shorter) and a higher selling price (approximately $3 \%$ more) than comparable houses with a red label (i.e. after taking into account differences in location, quality and year of construction). They also discovered that a better energy label score (e.g. A) does correlate with a lower average monthly gas costs for comparable houses, but that most people are neither interested nor aware of their energy consumption (with young high-income individuals having the lowest awareness levels) (Brounen et al. 2011). Thus, many households are unaware of how their household could conserve energy by having a better label score. Moreover, the Energy Center of the Netherlands (ECN) performed an EU-wide household analysis of consumer motivation and barriers related to the energy label. Their findings suggest that how the message for the label is framed (what motivational incentive and context are used as well as understandability) is as crucial as what kind of information is provided (Backhaus et al. 2011). For example, they find that people are particularly concerned about presentation and comfort when renovating their 
home. People are also more likely to adopt energy saving suggestions during renovations when these are presented in a comprehensible manner. They suggest exploring how to present the label as an avenue for further research.

Peoples' interests relate to the persistent question of how to motivate households to get a label and lower their energy consumption. Griskevicius et al. (2008) find that economists and policymakers often rely on costly financial incentives or developing expensive campaigns in order to mitigate climate change. In the Netherlands, governmental information campaigns "assume that people are persuaded more by arguments based on egoistic considerations" and design their campaigns to appeal to this type of audience (De Groot and Steg 2009, p. 64). De Groot and Steg (2009, p. 64) further claim that "these campaigns often fail to promote sustainable behavior" because they do not appeal to other values and potentially cheaper and more effective methods could be used to entice pro-environmental behavior. For example, Griskevicius et al. (2008) and Cialdini and Schultz (2004) claim that social norms are an underused tool for promoting climate change abatement and decreasing energy consumption.

Our paper extends the current literature by making use of a behavioral email experiment and online survey to assess the role of different motivational frames (egoistic/self-interest, biospheric/environmental, social norms and neutral/information only) in stimulating behavioral change and, in particular, adoption of energy labels for conservation. Furthermore, this is the first study to our knowledge that explores consumers' perceived value of an energy label through their willingness to pay (WTP) estimates and links this with their underlying socio-economic characteristics.

\section{Theoretical framework}

As energy labels try to solve an environmental problem, the assumption is that one needs to point out environmental values to motivate individuals to get labels in order to conserve more energy. However, the situation is often more complex in reality. Improving the effectiveness of information tools is linked to understanding and tapping into the right motivational frame of consumers (Steg and Vlek 2009). For this reason, the behavioral influence of available information (e.g. in terms of encouraging energy efficiency) is likely to be mediated by the way such information is framed (see Tangari and Smith 2012). Furthermore, evidence on environmental behavior also points to the fact that, although people may claim to care about the environment in general, they are often inconsistent in terms of their actual environmental behavior; for example, Steg and Vlek (2009) found that, in the Netherlands, even if people actively recycle or eat less meat, they do not necessarily conserve more energy than the average person. Thus, environmental messages may not necessarily motivate adoption of energy labels.

This research was inspired by the social normative research led by Cialdini et al. (1990) (see also Cialdini and Schultz 2004; Cialdini et al. 2006; Goldstein et al. 2008; Griskevicius et al. 2008; Nolan et al. 2008) that employed different motivational frames to see what framing would elicit the highest response to an environmental problem. For example, in one experiment the researchers left California residents door hangers with different motivational frames (biospheric, egoistic, social norms, social responsibility and neutral (information only) framing) to encourage individuals to use fans instead of air-conditioning (Cialdini and Schultz 2004). In this experiment, as well as other ones which use motivational frames to encourage towel and linen reuse (Goldstein et al. 2008), these researchers found that social norms were an effective (and non-costly) frame to encourage pro-environmental behavior. 
Due to the ongoing problem of active energy label adoption, we wanted to research whether social norms or other motivational frames were more effective in eliciting a response from Dutch residents to get an energy label. In our case, an email was sent to participants about the energy label (framed in four different ways) querying their interest in receiving an energy label. Four motivating frames we explore in this study are (1) egoistic motivations, (2) biospheric (environmental) concerns, (3) social norms and (4) neutral framing. Our research uses these frames to analyze which message(s) motivate(s) interest in the energy label in an online behavioral experiment. A separate online survey is used to understand the consumers' profile, WTP and their perception of the energy label as well as environmental problems. Egoistic motivations relate to self-enhancement values (that place focus primarily on self and self-oriented goals); these are explained by the theory of planned behavior that claims behavior is guided primarily by one's attitude and personal goals balanced with perceptions on behavioral consequences and social norms, which do not necessarily need to contradict one's personal aspirations (Ajzen 1991; Abrahamse and Steg 2009; Bamberg and Möser 2007; Steg and Vlek 2009). When egoistic motivations are prominent, the literature advocates making green products cheaper and more efficient, as well as offering financial incentives, such as subsidies and tax deductions (Griskevicius et al. 2010). Tangari and Smith (2012) find environmental messages to be more effective when they place emphasis on anticipated (monetary) benefits in the shorter term. This is because there is often a negative relationship between self-enhancement values and environmental action, with the latter often being framed as requiring some sort of sacrifice (Schultz 2001; Corraliza and Berenguer 2000; Schultz and Zelenzy 2003).

Biospheric values relate to the concern for the present and future well-being of the environment and biosphere (Schultz and Zelenzy 2003; De Groot and Steg 2010). To highlight biospheric values, information should make these people aware of the consequences of their actions on the physical and social environment and stress personal responsibility to act (Griskevicius et al. 2010; Steg and Vlek 2009).

Social norms relate to the belief of what is commonly done by others (e.g. peers, local community) and the importance of conforming with a certain expected social behavior (Griskevicius et al. 2010). The focus theory of normative conduct places emphasis on the ability of social norms to predict and alter human behavior (Cialdini et al. 2006). According to this theory, social norms relate to individual's desire to self-identify with a social group that one's behavior is being compared to (Griskevicius et al. 2008). When there is uncertainty (e.g. in terms of the timing and type of energy price shocks and climate change impacts), individuals tend to look at others to determine how they should act (i.e. determine what is the 'socially appropriate' behavior) (Cialdini et al. 2006).

Similar to the fan versus air-conditioning door hanger experiment (Cialdini and Schultz 2004; Nolan et al. 2008), a neutral (information only) framing is also used in our studythis is for sake of comparison against the other frames that incorporate a motivational message (egoistic, biospheric and social norms).

\section{Methods}

\subsection{Participants}

For the purposes of conducting our study, we approached 4000 randomly selected clients of a Dutch utility company in the spring of 2012, 3985 of which actually received the 
online survey. It is unknown how many individuals opened their email. A sub-sample of 3188 were invited to participate in the behavioral email experiment by email. The reason for excluding part of the sample from the behavioral experiment was to enable comparison between those who had received information through the behavioral experiment with those who did not. Sample composition is described in more detail in Sects. 3.2 and 3.3. A subsample of 333 individuals (i.e. response rate $10 \%$ ) responded to the email experiment that preceded the survey (see Sect. 3.2). Our sample for the online survey consists of 611 individuals who agreed to participate (see Sect. 3.3) (i.e. a response rate close to $15 \%$ ). Table 1 illustrates some key characteristics of the survey sample (of 611 respondents) compared to the general Dutch population.

The energy supplier's clients are located throughout the Netherlands with diverse living situations (Fig. 1). The majority of the survey respondents are involved in making decisions about energy in their households $(27.1 \%$ were solely responsible, $71.8 \%$ were jointly responsible). Female participants accounted for $33.5 \%$ of respondents and male participants $66.5 \%$. Although the sample was randomly selected, most of the respondents were homeowners. Information about actual annual gas and electricity consumption was provided by the utility company and was contrasted against self-reported survey data.

\subsection{The behavioral email experiment}

The experiment explored the role of different motivational frames (provided in an email message) in promoting interest in residential energy labels. Participants received one of the following messages that encouraged energy label adoption: (1) improving the environment (the biospheric frame), (2) saving money and improving comfort (the egoistic frame), (3) behaving similarly to other consumers (the social norm frame) and (4) neutral information about the role of an energy label in conserving energy (see Table 2 for the four email subject lines used in the experiment). The layout of the 4 emails was similar to the door hangers in Cialdini's experiment (e.g. Cialdini and Schultz 2004). For each message, different framing was applied to motivate lowering energy consumption and to briefly describe the label's benefits. To determine if individual were interested in the label based on the manner it was framed, a weblink was provided where they could sign-up for an online indication label (which is comparable to an unverified definite label) when it was available (for more specific information on the messages in Dutch please contact the corresponding author). A fifth group did not receive a behavioral experiment email and

Table 1 Comparison of survey sample versus Dutch population averages

\begin{tabular}{lll}
\hline & Sample average & Dutch average \\
\hline Annual gas consumption & $1904.6 \mathrm{~m}^{3}$ & $1600 \mathrm{~m}^{3}$ Milieu Centraal (2012) \\
& & $1850 \mathrm{~m}^{3} \mathrm{CBS}(2012 \mathrm{a})$ \\
Annual electricity consumption & $3523.24 \mathrm{kWh}$ & $3500 \mathrm{kWh}$ CBS (2012a) \\
Living situation & $13.4 \%$ Renters & $44.2 \%$ Renters \\
& $86.6 \%$ Homeowners & $55.1 \%$ Homeowners \\
& & $0.7 \%$ Unknown CBS (2012b) \\
Household size & 2.66 & 2.20 CBS (2015) \\
Age & $41-50$ or $4.40(1-6$ scale) & 41.10 Central Intelligence Agency (2012) \\
\hline
\end{tabular}




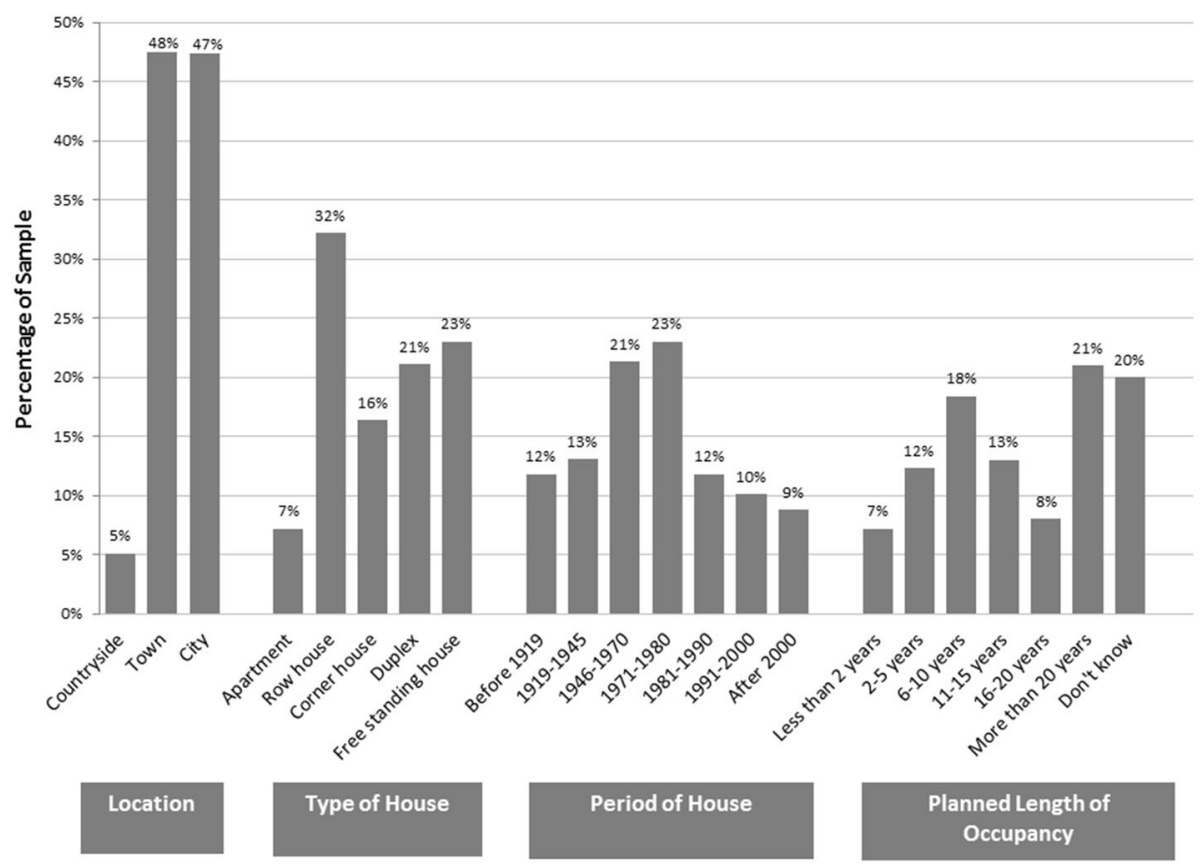

Fig. 1 Sample living conditions $(N=611)$. Note Some values may not add up to $100 \%$ due to rounding

Table 2 Motivational frames

\begin{tabular}{ll}
\hline Motivational frame & Email subject title \\
\hline Egoistic & Save money by conserving energy \\
& (Bespaar geld door zuiniger om te gaan met energie) \\
Biospheric & Protect the environment by conserving energy \\
& (Bescherm het milieu door energie te besparen) \\
Social norms & Join your neighbors in conserving energy \\
& (Vergelijk uw energieverbruik met uw buren) \\
Neutral information & Energy conservation \\
& (Energiebesparing) \\
\hline
\end{tabular}

Dutch text in parentheses

were only approached to complete the online survey at the same time as the other four groups. All five groups approached were of equal size (797 individuals).

To measure individuals' responses to the different motivational frames, a follow-up link to sign-up for the online energy label was included in the email for interested recipients. If the individuals chose to follow the link, they were then asked to confirm their interest (through a 'yes' or 'no' response) and provide contact information. Only individuals interested in the label were expected to click on the link. Thus, only 'yes' responses were expected although a few individuals did indicate 'no'. The behavioral experiment emails were sent out 6 days before the online survey was released to lower the perception that the email experiment was directly related to the survey. Only responses to the behavioral 
experiment emails received before the survey was launched were included in the analysis. Responding to the email experiment was not a prerequisite for filling in the subsequent online survey.

\subsection{The online survey and regression analysis}

The online survey asked respondents to identify the factors that motivate them to consider an energy label. The questionnaire was paired with actual energy consumption data in order to contrast individuals' actual and desired energy behavior. The questionnaire was designed to collect information on: (1) self-identified motivational factors behind energy label adoption; (2) socio-demographic characteristics of respondents; and (3) consumers' perceived monetary value or WTP for the label. Several questions aimed to capture the extent of egoistic, biospheric and social normative concerns across respondents as well as their trust in the energy label and local/government institutions as a source of information. Participants were probed on their perceived level of responsibility towards (1) resource depletion, (2) climate change and (3) general environmental problems, as well as their perceived level of energy efficiency. For several questions, we used a five (or seven) point Likert scale to measure the level of agreement with a given statement (see Albaum 1997). For example, respondents were questioned on the importance they attach to increasing their property value or lowering costs when deciding on energy efficiency on a 1-5 Likert scale (with larger values corresponding to higher importance). Appendix Table 6 provides a description of all variables, the scale at which they were measured, as well as references to the original studies that motivated us to include them in our analysis-for all variables we have adopted the same, or very similar, Likert scale as the ones used in these original studies. Respondents were also asked about their perceived WTP for an energy label. As customary in the literature, a payment card with 22 optional values (between 0 and more than $€ 1000$ ) accompanied the WTP question (based on Rowe et al. 1996, which assumes that people's ability to perceive differences decreases as the value increases). However, individuals were not constrained by this range and could opt for any possible positive value.

To explain the variation in WTP across respondents and its association with several respondent (and housing) specific characteristics, we performed a multivariate regression analysis estimating 10 different specifications varying the set of explanatory variables (see Table 4). The first specification only included socio-demographic variables (column 1). While keeping the socio-demographic variables in the analysis, we consecutively included in our empirical specification: building and tenancy characteristics (column 2), past and future renovation plans (column 3), perceived social responsibility for environmental problems (column 4), perceived ability to improve energy efficiency (column 5), perceived negative side-effects of energy conservation (column 6), perceived positive side-effects of energy conservation (column 7), trust (column 8) and a combination of all factors used for the regression analysis (column 9). In column 10 we only included explanatory variables that were found to be statistically significant in at least one of the first eight specifications tested. Regression analysis is a common statistical technique used to estimate the relationship between a dependent variable (WTP in this case) and a set of explanatory factors. The estimated coefficient for each explanatory variable corresponds to the predicted change in WTP for each one-unit difference in this particular explanatory variable (assuming that all other explanatory variables of the model are held constant). There is a detailed description of all of the variables in Appendix Table 6 and their descriptive statistics in Table 7. 


\section{Results}

\subsection{Behavioral email experiment}

A total of 317 energy consumers stated that 'yes' they were interest in receiving an energy label (from the sample of 3188 clients emailed; i.e. the four different message groups of 797 individuals each). The neutral frame received more positive responses (102) than any other category. The social norms frame had the second highest response rate (84), which was significantly higher compared to the biospheric framed message (and slightly higher than the egoistic framed message). A Pearson Chi square test $\left[\mathrm{c}^{2}(3, N=3188)=15.96\right.$ $p=.00]$ signified that these differences across the four motivational frames are statistically significant. Summary results are presented in Table 3. This is in line with earlier research stressing that neutrally framed messages are often more persuasive compared to messages that convey some form of obligation (see Kolyesnikova et al. 2011). Although social norms did not score the highest, the relative high response attributed to the social norm messages is consistent with earlier research by Goldstein et al. (2008). We also examined statistical differences in the positive response ('yes' reply to get energy label) across pairs of motivational frames. The statistical significance of the difference in the response rate is the highest for the neutral information and biospheric groups, followed by the biospheric and social norms.

\subsection{The online survey and regression analysis}

Our results (based on the primary data collected from the online survey) indicate that the average participant has a stronger than neutral feeling of responsibility for environmental problems [i.e. the average value for the level of responsibility for environmental problems is 3.66 in a 1 (no responsibility) to 5 (full responsibility) scale], see correlation table in Appendix Table 8. However, no significant correlation is detected between the perceived level of environmental responsibility and the actual gas consumption level. The results also illustrate that individuals have low expectations with respect to the energy label's added value. Most individuals (53\%) stated that they would only get a label if it were mandatory,

Table 3 Email experiment (responses)

\begin{tabular}{|c|c|c|c|c|c|}
\hline \multicolumn{3}{|c|}{ Email groups and intent to get an energy label } & \multicolumn{2}{|c|}{ Energy label } & \multirow[t]{2}{*}{ No. email recipients } \\
\hline & & & No & Yes & \\
\hline \multicolumn{6}{|l|}{ Group } \\
\hline $\begin{array}{l}\text { Egoistic } \\
\text { (self-interest) }\end{array}$ & & Count & 4 & 76 & 797 \\
\hline $\begin{array}{l}\text { Biospheric } \\
\text { (environment) }\end{array}$ & & Count & 7 & 55 & 797 \\
\hline Social norms & & Count & 5 & 84 & 797 \\
\hline Neutral information & & Count & 0 & 102 & 797 \\
\hline Total & & Count & 16 & 317 & 3188 \\
\hline & Value & \multicolumn{3}{|c|}{ Degrees of freedom } & Asymptotic significance \\
\hline Pearson Chi square & 15.96 & \multicolumn{3}{|l|}{3} & 0.00 \\
\hline
\end{tabular}


while few individuals $(<35 \%)$ cited the usefulness of getting a residential energy label to save energy.

On average, the participants' perceived value of an energy label is low. The average respondent's WTP for an energy label (for the 526 consumers, out of the 611 surveyed, who answered this particular question and, hence, provided the estimates) is $€ 74.11$ (more than $70 \%$ lower than the average market price before 2015, approximately $€ 200$ ). Figure 2 displays the cumulative distribution of the sample in terms of stated WTP. Only approximately $8 \%$ of the respondents are willing to pay the current average market price for an energy label. Almost $40 \%$ of the sample is not willing to pay more than $€ 25$, while approximately $29 \%$ of the sample opted for a zero value (i.e. no WTP).

The regression results of Table 4 indicate that age was the only socio-demographic factor that was consistently a significant predictor of WTP (a quadratic specification of age was also tested but was found to be statistically insignificant). Thus, the older people are, the more willing they are to invest in an energy label. This is in line with earlier evidence from the literature suggesting that older individuals often tend to be more interested in energy conservation (Brounen et al. 2011). We included the attribute renters and homeowners in the WTP regressions, but the results showed little difference between the two groups. This result should be interpreted with caution due to the small sample size of renters who participated in the survey. For this reason, this attribute was not analyzed separately in the WTP regression analysis. In the Netherlands, many individuals rent long-term, often through social housing corporations. Given their long-term occupancy, it is perhaps not surprising that their behavior can resemble the behavior of actual owners (e.g. installing floors and maintenance).

As one would expect, those who are occupying more recently built properties have a lower WTP, but the correlation is not statistically significant. Surprisingly, how long

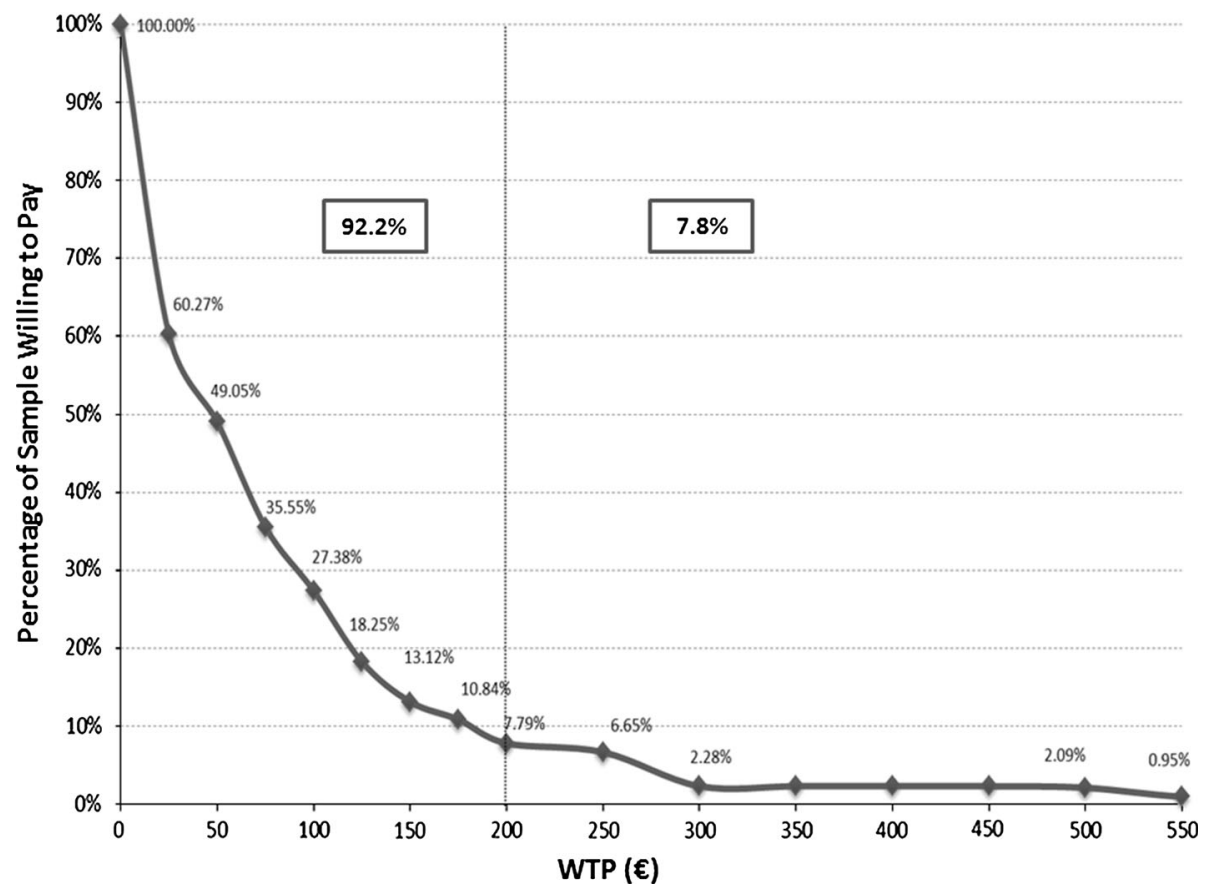

Fig. 2 Percentage of respondents willing to pay a given price for the label 


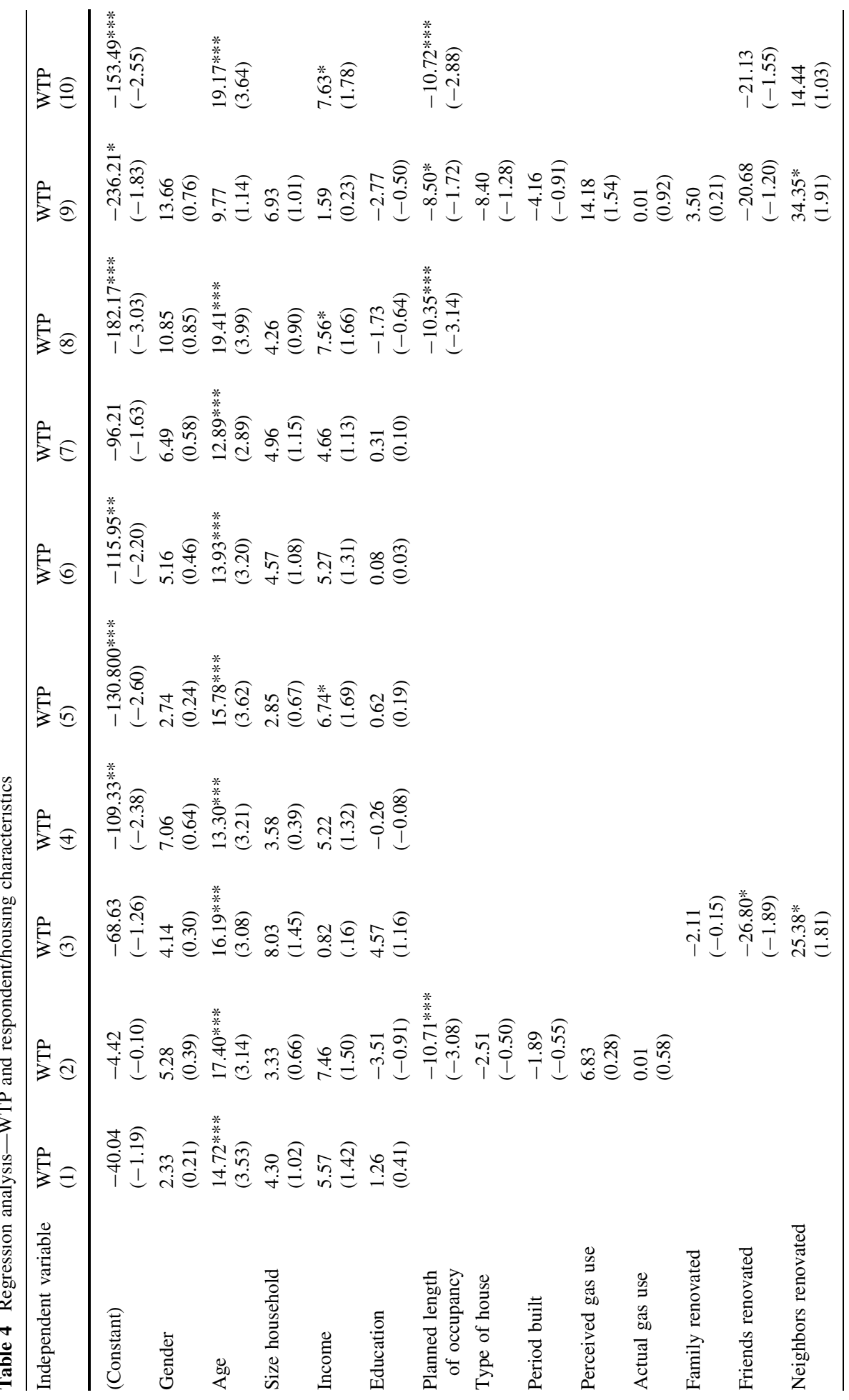




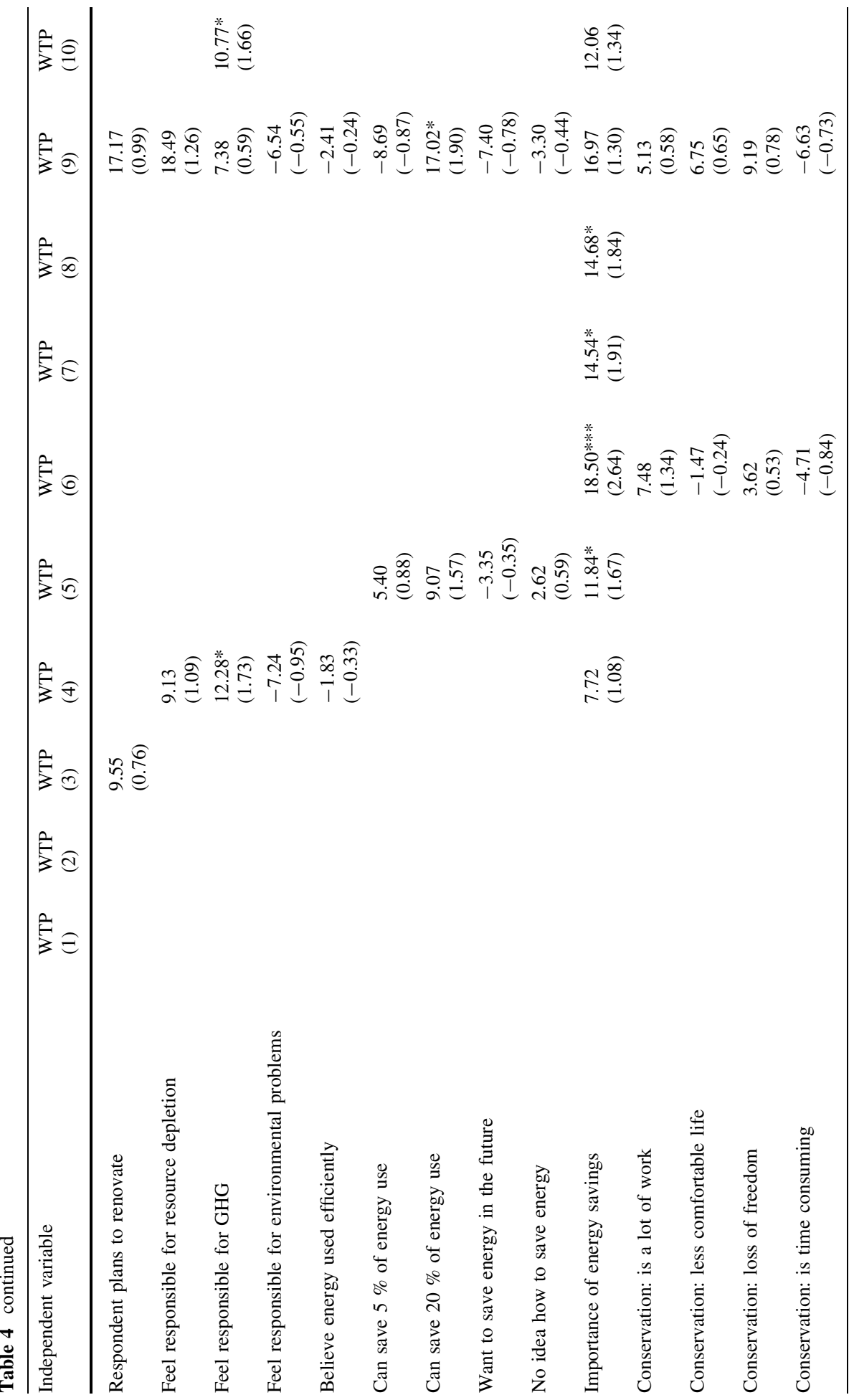




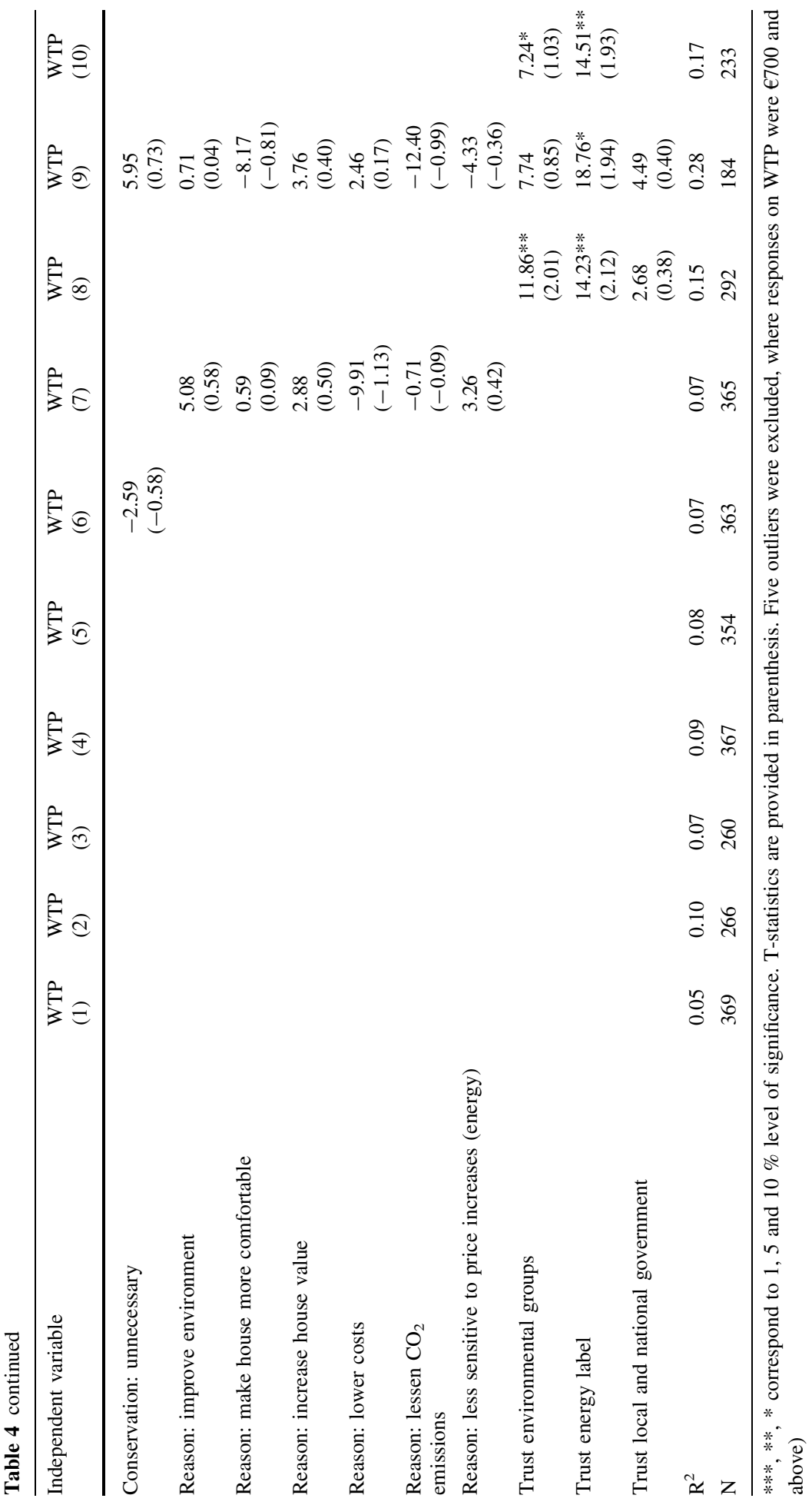


individuals plan to stay in the same home (planned occupancy duration) is negatively correlated with WTP (despite the fact that longer occupancy can provide an opportunity for higher accumulated benefits as a result of energy conservation; see Table 4 columns 2, 8, 9 and 10). However, this negative correlation can be attributed to the policy in place in the Netherlands of only requiring a residential energy label when buying, selling or renting a house. Many renters are unaware whether their residence has a label and what the label score is. Neither the perceived nor actual gas consumption is statistically significant in explaining the variation in WTP (although higher energy consumption is associated with a higher WTP). Having neighbors who financed an important renovation of their house in the previous year (costing more than $€ 1000$ ) appears to be a motivating factor behind adopting an energy label (columns 3 and 9). There is ample evidence in the literature pointing to the role of social connectivity (and particularly learning from neighbors) in diffusion of certain practices and technologies (e.g. Goldstein et al. 2008; Manski 2000).

As expected, the degree of importance attached to energy savings correlates positively [although weakly for specifications (4), (8) and (9)] with the WTP level for an energy label (see Table 4). In terms of assuming responsibility for the environment, only a sense of responsibility for minimizing GHGs significantly explains WTP for energy labels (columns 4 and 10). The perceived ability to contribute to energy conservation as well as the motivating factors related to either negative or positive side-effects of energy label adoption appear to have weak statistical power in explaining WTP levels. In other words, respondents do not strongly associate a residential energy label with specific energy conservation goals they might wish to pursue (see columns 5-7). On the other hand, trust in environmental organizations and the energy label as sources of information for energy conservation is positively associated with increased WTP (by $€ 11.86$ and $€ 14.23$ respectively; see column 8). This is in line with empirical work pointing to a close relationship between self-efficacy (own ability to reach goals) and trust in institutions (e.g. there is much evidence suggesting that trust in information renders individuals more proactive and raises the rate of adoption of certain technologies-e.g. see Lee and Lin (2009) and Bélanger and Carter (2008) for the role of trust in influencing behavior and technology adoption in medicine and the IT sector. Blake (1999) also claims that lack of trust is often one of the key barriers behind limited pro-environmental behavior.

We also tested whether the WTP for an energy label varies significantly across the five different groups: i.e. the four groups who received the differently framed messages of the email experiment, as well as the fifth group that only participated at the online survey (see Table 5). There was a significant effect at the $p<.10$ level of the different message framing on WTP $[F(4,521)=2.20, p=.068]$. The group that received the biospheric message expressed the highest WTP $(€ 105.38)$, while the group that received the egoistic

Table 5 Comparison of average WTP across five groups

\begin{tabular}{lrrr}
\hline Group & Mean & N & Std. deviation \\
\hline Egoistic & 60.11 & 108 & 108.38 \\
Biospheric & 105.38 & 93 & 166.50 \\
Social norms & 74.34 & 94 & 123.06 \\
Neutral information & 65.96 & 116 & 85.44 \\
Group not participating in the email experiment & 69.99 & 115 & 100.45 \\
Total & 74.11 & 526 & 118.14 \\
\hline
\end{tabular}

ANOVA $[F(4,521)=2.20, p=.068]$ 
message expressed the lowest average WTP (€60.11). Hence, while messages with a biospheric motivation triggered the lower response rates in our email experiment, those who received them expressed the highest average WTP levels for residential energy labels. Both the groups that received the egoistic and neutral message types have lower average WTP than the group that did not receive the email experiment.

\section{Discussion}

The study sets out to assess the role of different factors in motivating energy conservation through energy labels. First, we demonstrate that how a message is framed can affect the response rate. In our email experiment, neutral information performed the best in promoting interest in the residential energy label. This suggests that the neutral framing of the message may improve the credibility of energy labels, particularly considering their negative past publicity. Nonetheless, social norms can still play a role in motivating people to get an energy label given their relatively high response rate and WTP. At the same time, although the goal is to promote environmental outcomes, this study indicates that Dutch households are the least motivated, in terms of response rate, to get a label when the biospheric frame is applied. The egotistic frame, traditionally used in Dutch governmental information campaigns (De Groot and Steg 2009), had a relatively low response rate along with the lowest WTP. The findings suggest that policymakers need to consider alternative approaches to the traditional egotistic framing or exclusive dependence on biospheric framing in order to increase response levels.

The study's findings suggest that, in general, the response rate to a message framing is not indicative of the WTP level (i.e. a higher response rate does not mean a higher WTP). The results indicate that those who received neutral framed or social norms based messages (compared to biospheric ones) had the highest response rates but not the highest WTP. The group that received the biospheric message expressed the highest WTP $(€ 105.38)$, while the group that received the egoistic message expressed the lowest average WTP (€60.11), but had a relatively low response rate. Different groups have different average WTP, but of course label providers offer clients a uniform price-this suggests that the success of the energy label initiative would require appropriately framed messages in combination with a pricing scheme (of sufficiently low rates) that takes into consideration the differences in WTP across groups/messages.

A socio-demographic factor contributing to high WTP is age. These results are in line with those obtained by Brounen et al.'s (2011) that young (and high-income) individuals have the lowest awareness levels of energy consumption. Making energy conservation more meaningful for young people is an important issue for future research. Policymakers should realize that younger energy consumers have both lower awareness and are more resistant to paying for an energy label.

We observe a high level of resistance to paying for an energy label, as indicated by the $28.7 \%$ of respondents who opted for a zero WTP for a label. As of 2015, the provisional label is free and the definite label costs 'a few bucks' (Rijksoverheid 2015). The changes made in 2015 are better aligned with peoples' WTP shown in this study. However, although the current label has the benefits of low cost, the accuracy and added value of the information provided are questionable as indicated by previous research (Backhaus et al. 2011; Brounen and Kok 2011a; Majcen et al. 2013a, b). The cheaper price comes at the expense of not having a personalized inspection of the property's energy efficiency nor tailored recommendations. 
A possible explanation for the resistance to pay for the label is that few individuals find the label useful. Contrary to expectations, the findings suggest that the length of occupancy is negatively correlated to WTP for an energy label. Many respondents express an interest in having a label only when mandatory, while few respondents acknowledge any perceived potential benefits of the label. The current policy focuses on those selling or renting to others. However, this is not the group that is likely to make improvements to the energy efficiency of buildings while renovating. Greater efforts are needed to ensure that long-term occupants, who have the potential to benefit from improved energy efficiency, use the label. Clear communication of the type of information the energy label provides and the anticipated benefits of residential energy labels (that accrue to individuals, the natural environment as well as the society as a whole) could incentivize long-term occupants to use the label.

However, the amended energy label policies still focus on mandatory requirements (which can be opted out of up until the last moment) instead of improving the label's usefulness and matching consumers' interests with energy conservation. The energy label program's goal is to lower emissions through energy conservation. However, unless individuals are motivated to use the label's information to improve energy efficiency in the housing stock, the label remains a window dressing instead of aiding energy conservation.

Acknowledgments The corresponding author is grateful to Greenchoice in the Netherlands for an internship invitation that enabled and supported this research, as well as to Professor Robert Cialdini for providing useful comments on an earlier draft.

Open Access This article is distributed under the terms of the Creative Commons Attribution 4.0 International License (http://creativecommons.org/licenses/by/4.0/), which permits unrestricted use, distribution, and reproduction in any medium, provided you give appropriate credit to the original author(s) and the source, provide a link to the Creative Commons license, and indicate if changes were made.

\section{Appendix}

See Tables 6, 7 and 8 .

Table 6 Variables description

WTP

Gender

Age

Size household

Income

Education level

Planned length of occupancy
Question asked how willing the individual is to pay for an energy label if it is mandatory and has the purpose of informing the individual of their house's energy efficiency and of giving advice on how to improve the energy efficiency. Values on payment card from $€ 0$ to $€ 1000$

Discrete: female, male

6-point scale: $<20 ; 21-30 ; 31-40 ; 41-50 ; 50-65 ; 65+$

Number of people in household including respondent Interval scale: 1, 2, 3, 4, 5+

Continuous scale of gross income with option not to answer $€ 0-1000$; €1000-2000; €2000-3000; €3000-4000; €4000-5000; €5000+

Based on the Dutch educations system

12-point scale from lower to higher educational attainment

The number of years the individual plans to remain at the current address Scale: $<2$ years; $2-5$ years; $6-10$ years; $11-15$ years; $16-20$ years; more than 20 years; I don't know 
Table 6 continued

Type of house

Period built

Perceived gas use

Actual gas use

Actual electricity use

Actual label score

Perceived label score

Family renovated

Friends renovated

Neighbors renovated

Respondent plans to renovate

Feel responsible for resource depletion

Feel responsible for GHG

Feel responsible for environmental problems
The type of house the respondent lives in, going from a structure that has walls with the least amount of exposure to outer climate to the most Apartment; row house; corner house; duplex; free standing house

Period of house built. Buildings constructed during the same period generally had the same level of insulation

Discontinuous scale: before 1919; 1919-1945; 1946-1970; 1971-1980; 1981-1990; 1991-2000; after 2000; I don't know

Question asked whether the respondent thinks that they consume more or less gas than the Dutch average of $1600 \mathrm{~m}^{3}$ per year

Likert scale (1-5): much less than average; less than average; average; more than average; much more than average; I don't know

Value is respondent's gas consumption for the past year $\left(\mathrm{m}^{3} / \mathrm{a}\right)$

Value is respondent's electricity consumption for the past year (kWh/a)

Only respondents who answered 'yes' to whether they had an energy label were asked this question. The respondent was asked what rating their house received from the existing label scale of $\mathrm{A}-\mathrm{G}$ where A denotes an energy efficient house and $\mathrm{G}$ denotes a very inefficient house.

Scale: (1-7, where $\mathrm{A}=1, \mathrm{~B}=2)$

Respondents who answered 'no' or 'maybe' to whether they had an energy label were asked this question. Respondent were asked what rating their house received from the existing label scale of $A-G$ where A denotes an energy efficient house and $\mathrm{G}$ denotes a very inefficient house.

Scale: $(1-7$, where $\mathrm{A}=1, \mathrm{~B}=2)$

Question asked whether a family member financed a renovation for more than $€ 1000$ in the past 12 months. Inspired by Adjei et al. (2012)

Yes; no; I don't know

Question asked whether a friend financed a renovation for more than $€ 1000$ in the past 12 months. Inspired by Adjei et al. (2012)

Yes; no; I don't know

Question asked whether a friend financed a renovation for more than $€ 1000$ in the past 12 months. Inspired by Adjei et al. (2012)

Yes; no; I don't know

Question asked whether the respondent expects to renovate in the next 3 years. Inspired by Adjei et al. (2012)

Yes; no

Question asked to what degree the respondent dis/agrees with the statement that their energy consumption contributes to resource depletion. Based on research by Abrahamse and Steg $(2009 ; 2011)$ on the level of perceived responsibility for environmental problems stating that attitude and values are important indicators of environmental conservation

Likert scale 1-5: completely disagree to completely agree

Question asked to what degree the respondent dis/agrees with the statement that their energy consumption contributes to GHG. Based on research by Abrahamse and Steg $(2009,2011)$ on the level of perceived responsibility for environmental problems stating that attitude and values are important indicators of environmental conservation

Likert scale 1-5: completely disagree to completely agree

Question asked to what degree the respondent dis/agrees with the statement that their energy consumption contributes to general environmental problems. Based on research by Abrahamse and Steg $(2009,2011)$ on the level of perceived responsibility for environmental problems stating that attitude and values are important indicators of environmental conservation

Likert scale 1-5: completely disagree to completely agree 
Table 6 continued

Believe energy used efficiently Question asked to what degree the respondent dis/agrees with the statement that they already efficiently consume energy. Based on research by Abrahamse and Steg $(2009,2011)$ on the level of perceived responsibility for environmental problems stating that attitude and values are important indicators of environmental conservation and by Cialdini and Schultz (2004)

Can save $5 \%$ of energy use

Likert scale 1-5: completely disagree to completely agree

Question asked to what degree the respondent dis/agrees with the statement that it would be easy to save $5 \%$ of their household consumption. Refers to the concept of perceived behavioral control inspired by research by Abrahamse and Steg (2011)

Likert scale 1-5: completely disagree to completely agree

Can save $20 \%$ of energy use Question asked to what degree the respondent dis/agrees to the statement that it would be easy to save $20 \%$ of their household consumption.

Refers to the concept of perceived behavioral control, specifically how capable they feel they are for conserving energy, inspired by research by Abrahamse and Steg (2011)

Likert scale 1-5: completely disagree to completely agree

Want to save energy in the future

Question asked to what degree the respondent dis/agrees to the statement that they want to lower their future energy consumption. Refers to the concept of perceived behavioral control inspired by research by Abrahamse and Steg (2011)

Likert scale 1-5: completely disagree to completely agree

No idea how to save energy

Question asked to what degree the respondent dis/agrees to the statement that they do not know how they could use less energy. Refers to the concept of perceived behavioral control inspired by research by Abrahamse and Steg (2011)

Likert scale 1-5: completely disagree to completely agree

Importance of energy savings Inspired by value-belief-norms theory on how values motivate energy conservation behavior Steg and Vlek (2009), Stern (2000) and work by Cialdini and Schultz (2004)

Likert scale 1-5: entirely unimportant to completely important

Conservation: is a lot of work

Question asked to what degree the respondent dis/agrees to the statement that energy conservation is a lot of work in order to gauge the respondent's perception of energy saving Abrahamse and Steg (2009, 2011)

Likert scale 1-5: completely disagree to completely agree

Conservation: less comfortable life

Question asked to what degree the respondent dis/agrees to the statement that energy conservation means experiencing less living comfort in order to gauge the respondent's perception of energy saving Abrahamse and Steg $(2009,2011)$

Likert scale 1-5: completely disagree to completely agree

Conservation: loss of freedom Question asked to what degree the respondent dis/agrees to the statement that energy conservation limits personal freedom in order to gauge the respondent's perception of energy saving Abrahamse and Steg (2009, 2011)

Likert scale 1-5: completely disagree to completely agree

Conservation: is time consuming

Question asked to what degree the respondent dis/agrees to the statement that energy conservation costs too much time to realize energy savings in order to gauge the respondent's perception of energy saving Abrahamse and Steg (2009, 2011), Cialdini and Schultz (2004)

Likert scale 1-5: completely disagree to completely agree 
Table 6 continued

Conservation: unnecessary

Reason: improve environment

Reason: make house more comfortable

Reason: increase house value

Reason: lower costs

Reason: lessen $\mathrm{CO}_{2}$ emissions

Reason: less sensitive to price increases (energy)

Trust environmental groups

Trust energy label

Trust local and national government
Question asked to what degree the respondent dis/agrees to the statement that they have already done everything to conserve energy in order to gauge the respondent's perception of energy saving Abrahamse and Steg (2009, 2011)

Likert scale 1-5: completely disagree to completely agree

Question asked how important is improving the environment to the individual as a benefit of making their home more energy efficient. Inspired by personal norm and motivation research by Cialdini and Schultz (2004) and Sütterlin et al. (2011)

Likert scale 1-5: completely unimportant; unimportant; neutral; important; very important

Question asked how important is making their home more comfortable to the individual as a benefit of making their home more energy efficient. Inspired by personal norm and motivation research by Cialdini and Schultz (2004) and Sütterlin et al. (2011)

Likert scale 1-5: completely unimportant; unimportant; neutral; important; very important

Question asked how important is improving the house's value to the individual as a benefit of making their home more energy efficient. Inspired by personal norm and motivation research by Cialdini and Schultz (2004) and Sütterlin et al. (2011)

Likert scale 1-5: completely unimportant; unimportant; neutral; important; very important

Question asked how important is lowering energy costs to the individual as a benefit of making their home more energy efficient. Inspired by personal norm and motivation research by Cialdini and Schultz (2004) and Sütterlin et al. (2011)

Likert scale 1-5: completely unimportant; unimportant; neutral; important; very important

Question asked how important is lowering $\mathrm{CO}_{2}$ emissions to the individual as a benefit of making their home more energy efficient. Inspired by personal norm and motivation research by Cialdini and Schultz (2004) and Sütterlin et al. (2011)

Likert scale 1-5: completely unimportant; unimportant; neutral; important; very important

Question asked how important is being less sensitive to higher energy prices in the future to the individual as a benefit of making their home more energy efficient. Inspired by personal norm and motivation research by Cialdini and Schultz (2004) and Sütterlin et al. (2011)

Likert scale 1-5: completely unimportant; unimportant; neutral; important; very important

Question asked how trustworthy the respondent found environmental groups as a source of information for personal energy consumption. Based on the survey conducted by ECN Adjei et al. (2012)

Likert scale 1-5: completely untrustworthy to completely trustworthy

Question asked how trustworthy the respondent found the energy label as a source of information for personal energy consumption. Based on the survey conducted by ECN (Adjei et al. 2012)

Likert scale 1-5: completely untrustworthy to completely trustworthy

Question asked how trustworthy the respondent found the local and national government as a source of information for personal energy consumption. Based on the survey conducted by ECN Adjei et al. (2012)

Likert scale 1-5: Completely untrustworthy to completely trustworthy 
Table 7 Descriptive statistics

\begin{tabular}{|c|c|c|c|c|c|}
\hline Variable & Number & Mean & Minimum & Maximum & $\begin{array}{l}\text { Standard } \\
\text { deviation }\end{array}$ \\
\hline WTP & 526 & 74.11 & 0 & 1000 & 118.14 \\
\hline Gender & 534 & 1.66 & 1 & 2 & .473 \\
\hline Age & 536 & 4.40 & 2 & 6 & 1.12 \\
\hline Size household & 537 & 2.66 & 1 & 5 & 1.17 \\
\hline Income & 391 & 4.32 & 1 & 6 & 1.46 \\
\hline Education & 523 & 6.35 & 1 & 8 & 1.75 \\
\hline Planned length of occupancy & 486 & 3.81 & 1 & 6 & 1.67 \\
\hline Type of house & 608 & 3.20 & 1 & 5 & 1.31 \\
\hline Period built & 601 & 3.76 & 1 & 7 & 1.75 \\
\hline Perceived gas use & 548 & 3.19 & 1 & 5 & 1.14 \\
\hline Actual gas use & 4000 & 1904.60 & 746.49 & 1001 & 8142 \\
\hline Actual electricity use & 4000 & 3523.24 & 1416.46 & 512 & 6996 \\
\hline Actual label score & 51 & 3.55 & 1 & 7 & 1.85 \\
\hline Perceived label score & 525 & 3.38 & 1 & 7 & 1.47 \\
\hline Family renovated & 492 & 1.59 & 1 & 2 & 0.49 \\
\hline Friends renovated & 446 & 1.61 & 1 & 2 & 0.49 \\
\hline Neighbors renovated & 473 & 1.65 & 1 & 2 & 0.48 \\
\hline Respondent plans to renovate & 589 & 1.69 & 1 & 2 & 0.46 \\
\hline Feel responsible for resource depletion & 580 & 3.85 & 1 & 5 & 1.10 \\
\hline Feel responsible for GHG & 580 & 3.59 & 1 & 5 & 1.16 \\
\hline $\begin{array}{l}\text { Feel responsible for environmental } \\
\text { problems }\end{array}$ & 578 & 3.66 & 1 & 5 & 1.15 \\
\hline Believe energy used efficiently & 580 & 3.80 & 1 & 5 & 0.88 \\
\hline Can save $5 \%$ of energy use & 560 & 3.83 & 1 & 5 & 1.07 \\
\hline Can save $20 \%$ of energy use & 559 & 2.44 & 1 & 5 & 1.08 \\
\hline Want to save energy in the future & 559 & 3.90 & 1 & 5 & 0.99 \\
\hline No idea how to save energy & 558 & 2.41 & 1 & 5 & 1.16 \\
\hline Degree value energy savings & 572 & 4.38 & 1 & 5 & 0.73 \\
\hline Conservation: is a lot of work & 566 & 2.10 & 1 & 5 & 0.97 \\
\hline Conservation: less comfortable life & 567 & 2.06 & 1 & 5 & 0.97 \\
\hline Conservation: loss of freedom & 568 & 1.95 & 1 & 5 & 0.89 \\
\hline Conservation: is time consuming & 566 & 2.32 & 1 & 5 & 0.95 \\
\hline Conservation: unnecessary & 569 & 2.96 & 1 & 5 & 1.04 \\
\hline Reason: improve environment & 560 & 4.04 & 1 & 5 & 0.73 \\
\hline Reason: make house more comfortable & 559 & 3.87 & 1 & 5 & 0.74 \\
\hline Reason: increase house value & 560 & 3.49 & 1 & 5 & 0.88 \\
\hline Reason: lower costs & 559 & 4.18 & 1 & 5 & 0.65 \\
\hline Reason: lessen $\mathrm{CO}_{2}$ emissions & 559 & 3.93 & 1 & 5 & 0.81 \\
\hline $\begin{array}{l}\text { Reason: less sensitive to price increases } \\
\text { (energy) }\end{array}$ & 558 & 4.06 & 1 & 5 & 0.72 \\
\hline Trust environmental groups & 544 & 3.30 & 1 & 5 & 0.99 \\
\hline Trust energy label & 545 & 3.43 & 1 & 5 & 0.86 \\
\hline Trust local and national government & 540 & 3.40 & 1 & 5 & 0.86 \\
\hline
\end{tabular}




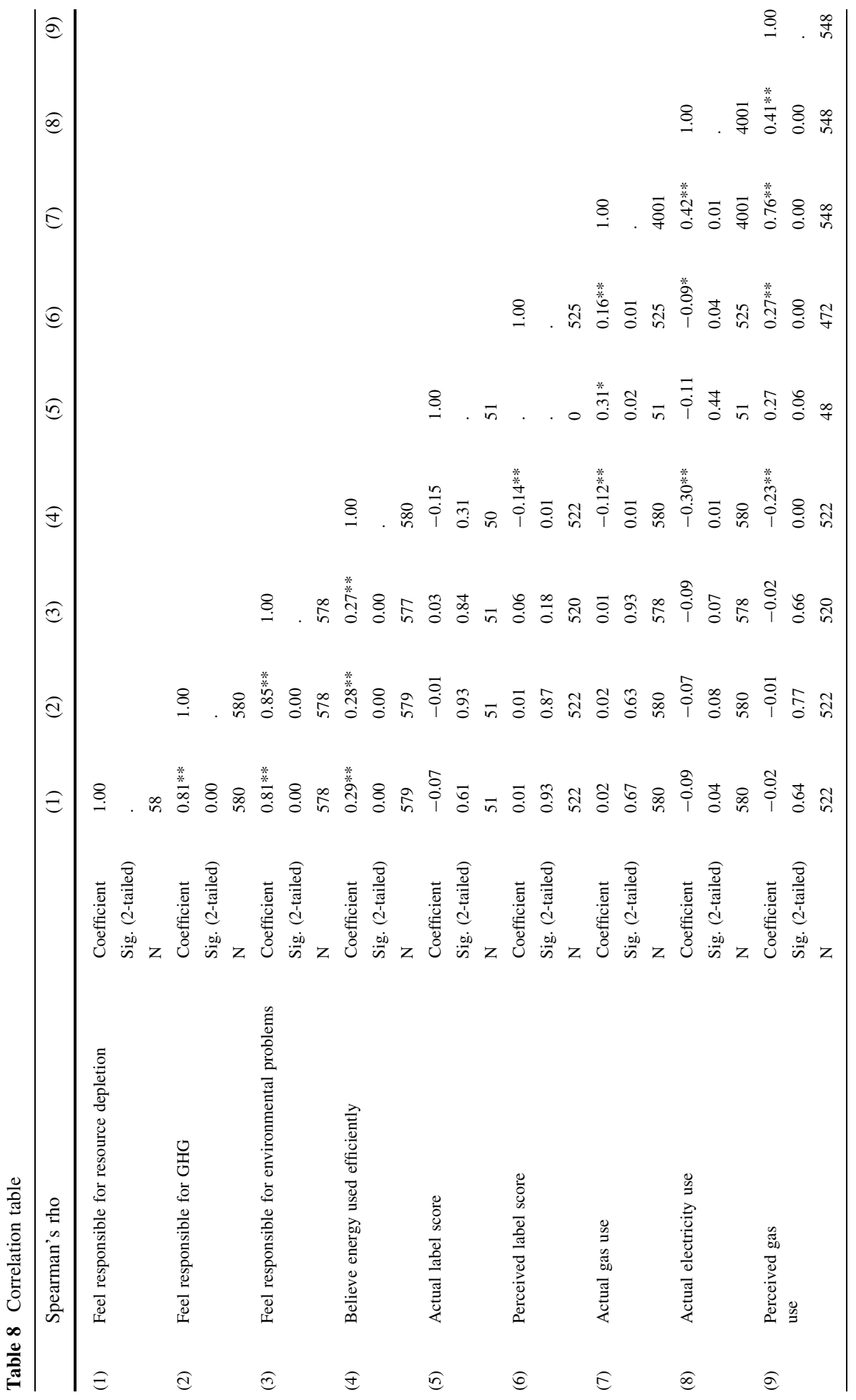




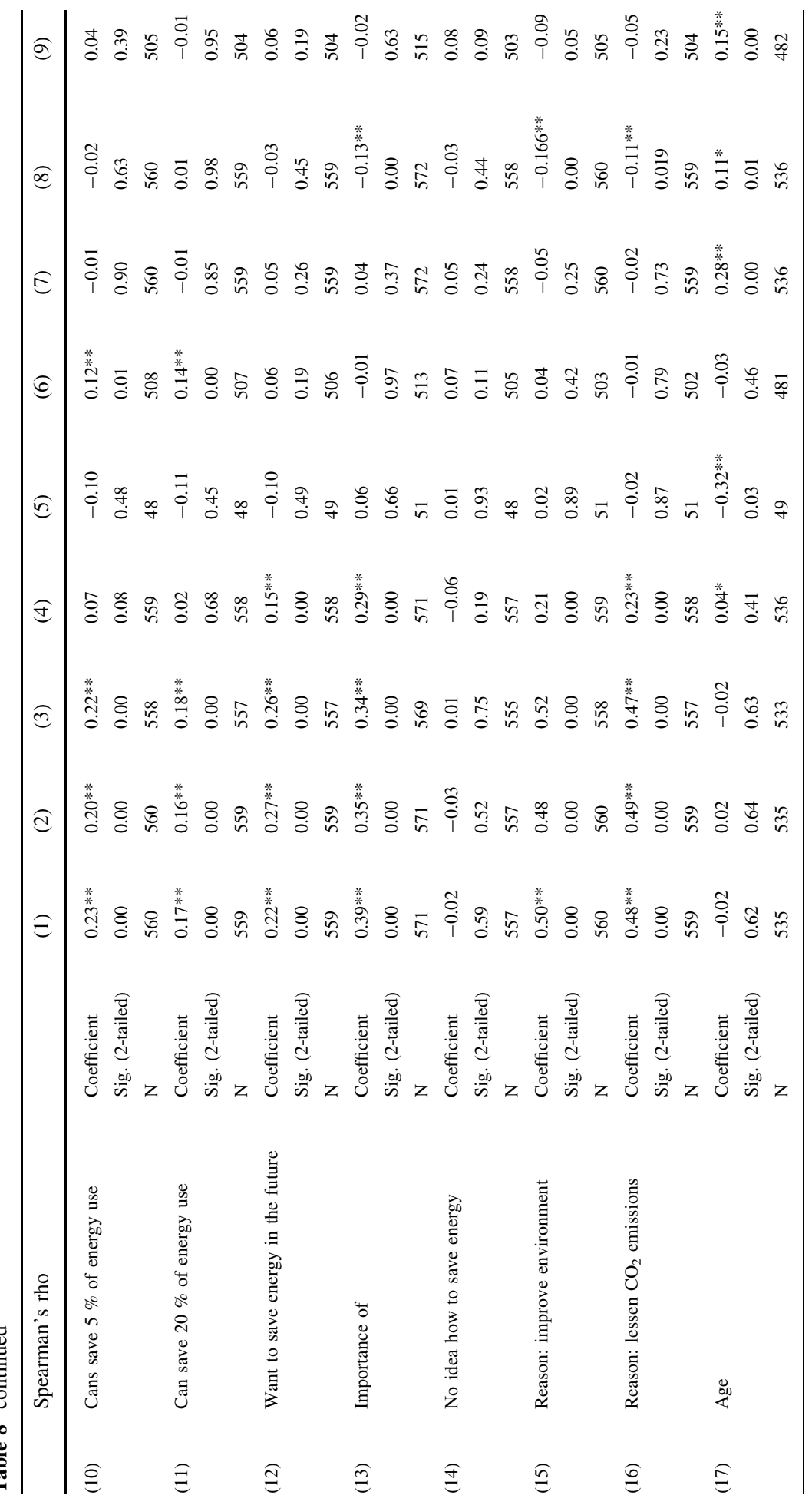




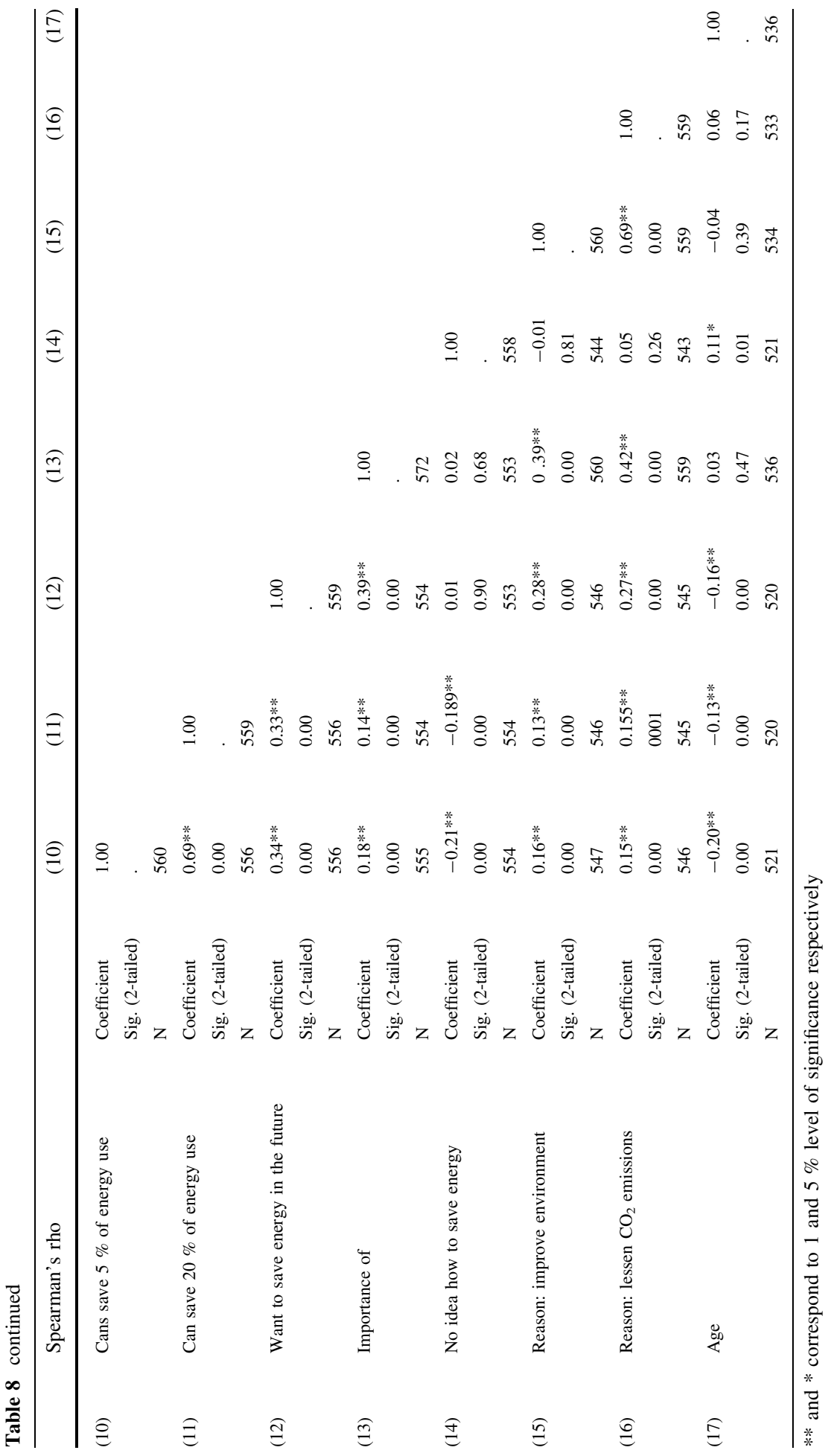




\section{References}

Abrahamse, W., \& Steg, L. (2009). How do socio-demographic and psychological factors relate to households' direct and indirect energy use and savings? Journal of Economic Psychology, 30, 711-720.

Abrahamse, W., \& Steg, L. (2011). Factors related to household energy use and intention to reduce it: The role of psychological and socio-demographic variables. Human Ecology Review, 18, 30-40.

Abrahamse, W., Steg, L., Vlek, C., \& Rothengatter, T. (2007). The effect of tailored information, goal setting, and tailored feedback on household energy use, energy-related behaviors, and behavioral antecedents. Journal of Environmental Psychology, 27, 265-276.

Adjei, A., Hamilton, L., \& Roys, M. (2012). Deliverable 5.2: A study of homeowners' energy efficiency improvements and the impact of the energy performance certificate. (The Netherlands: IDEAL EPBD (Improved Dwellings by Enhancing Actions on Labeling for the Energy Performance of Buildings Directive)).

Agentschap, N. L. (2011). EPBD/energielabel: Beleidskader. http://www.agentschapnl.nl/programmasregelingen/beleidskader. Retrieved from June 8, 2012.

Ajzen, I. (1991). The theory of planned behavior. Organizational Decision and Human Decision Process, 50, 179-211.

Albaum, G. (1997). The likert scale revisited: An alternate version. Journal of the Market Research Society, 39, 331-348.

Backhaus, J., Tigchelaar, C., \& de Best-Waldhober, M. (2011). Key findings and policy recommendations to improve effectiveness of energy performance certificates and the energy performance of buildings directive. (The Netherlands: IDEAL EPBD (Improved Dwellings by Enhancing Actions on Labeling for the Energy Performance of Buildings Directive)).

Bamberg, S., \& Möser, G. (2007). Twenty years after Hines, Hungerford, and Tomera: A new meta-analysis of psycho-social determinants of pro-environmental behaviour. Journal of Environmental Psychology, 27, 14-25.

Banerjee, A., \& Solomon, B. (2003). Eco-labeling for energy efficiency and sustainability: A meta-evaluation of US programs. Energy Policy, 31, 109-123.

Bélanger, F., \& Carter, L. (2008). Trust and risk in e-government adoption. Journal of Strategic Information Systems, 17, 165-176.

Blake, J. (1999). Overcoming the 'value-action gap' in environmental policy: Tensions between national policy and local experience. Local Environment, 4, 257-278.

Brounen, D., \& Kok, N. (2011a). On the economics of energy labels in the housing markets. Journal of Environmental Economics and Management, 62, 166-179.

Brounen, D., \& Kok, N. (2011b). Het energielabel op de Koopwoningmarkt: De laatste stand van zaken. (Research provided for the Ministerie van Binnenlandse Zaken). http://www.rijksoverheid.nl/ documenten-en-publicaties/rapporten/2011/04/11/het-energielabel-op-de-koopwoningmarkt.html. Retrieved from May 30, 2012.

Brounen, D., Kok, N., \& Quigley, J. (2011). Residential energy literacy and capitalization. (Research provided for the European Centre of Corporate Engagement (ECCE) and AgentschapNL). http://www. econtrack.nl/uploads/document/Energy\%20Literacy.pdf. Retrieved from June 18, 2012.

Brounen, D., Kok, N., \& Quigley, J. (2012). Residential energy use and conservation: Economics and demographics. European Economic Review, 56, 931-945.

CBS. (2009). Housing and energy costs weigh heavy on lowest incomes (July 19, 2009). http://www.cbs.nl/ en-GB/menu/themas/inkomenbestedingen/publicaties/artikelen/archief/2009/2009-2846wm.htm. Retrieved from October 24, 2013.

CBS. (2012a). Gas en elektriciteitsverbruik per woning het laagst in stedelijke gebieden (January 16, 2012). http://www.cbs.nl/nl-NL/menu/themas/bouwen-wonen/publicaties/artikelen/archief/2012/2012-energie verbruik-woningtype-art.htm. Retrieved from July 17, 2012.

CBS. (2012b). Woningvoorraad naar eigendom; regio (July 3, 2012). http://statline.cbs.nl/StatWeb/ publication/?VW=T\&DM=SLNL\&PA=71446NED\&D1=0-2,4-5\&D2=0,5-16\&D3=a\&HD=100419$1534 \& H D R=T, G 2 \& S T B=G 1$. Retrieved from March 20, 2013.

CBS. (2015). Huishoudens; grootte, samenstelling, positie in het huishouden, 1 januari 1995-2013, period 2012 (February 16, 2015). http://statline.cbs.nl/Statweb/publication/?DM=SLNL\&PA=37312\&D1= $\mathrm{a} \& \mathrm{D} 2=17 \& H D R=\mathrm{G} 1, \mathrm{~T} \& \mathrm{VW}=\mathrm{T}$. Retrieved from September 25, 2015.

Central Intelligence Agency. (2012). Median age. The world factbook. https://www.cia.gov/library/ publications/the-world-factbook/fields/2177.html. Retrieved from May 25, 2012.

Cialdini, R., Demaine, L., Sagarin, B., Barrett, D., Rhoads, K., \& Winter, P. (2006). Managing social norms for persuasive impact. Social Influence, 1, 3-15. 
Cialdini, R., Reno, R., \& Kallgren, C. (1990). A focus theory of normative conduct: Recycling the concept of norms to reduce littering in public places. Journal of Personality and Social Psychology, 58, 1015-1026.

Cialdini, R., \& Schultz, W. (2004). Understanding and motivating energy conservation via social norms. (Report prepared for the William and Flora Hewlett Foundation).

Corraliza, J., \& Berenguer, J. (2000). Environmental values, beliefs, and actions: A situational approach. Environment and Behavior, 32, 832-848.

De Groot, J., \& Steg, L. (2009). Mean or green: Which values can promote stable pro-environmental behavior? Conservation Letters, 2, 61-66.

De Groot, J., \& Steg, L. (2010). Relationships between value orientations, self-determined motivational types and pro-environmental behavioural intentions. Journal of Environmental Psychology, 30, 368-378.

EEP. (2013). Europe's energy portal: Electricity prices. http://www.energy.eu. Retrieved from October 25, 2013.

Europa. (2015). Summaries of EU legislations. Energy performance of buildings. http://eur-lex.europa.eu/ legal-content/EN/TXT/?uri=URISERV:en0021. Retrieved from September 25, 2015.

Goldstein, N., Cialdini, R., \& Griskevicius, V. (2008). A room with a viewpoint: Using normative appeals to motivate environmental conservation in a hotel setting. Journal of Consumer Research, 35, 1-11.

Griskevicius, V., Cialdini, R., \& Goldstein, N. (2008). Social norms: An underestimated and underemployed lever for managing climate change. International Journal for Sustainability Communication, 3, 5-13.

Griskevicius, V., Tybur, J., \& van den Bergh, B. (2010). Going green to be seen: Status, reputation, and conspicuous conservation. Journal of Personality and Social Psychology, 98, 392-404.

IDEAL EPBD. (2011) Wat is de EPBD? http://www.ideal-epbd.eu/index.php?option=com_content\&view= article\&id=2\&Itemid=2\&lang=nl. Retrieved from July 19, 2012.

Kolyesnikova, N., Sullivan Dodd, S., \& Callison, C. (2011). Consumer affective responses to direct mail messages: The effect of gratitude and obligation. Journal of Marketing Communications, 17, 337-353.

Lee, Y., \& Lin, J. (2009). The effects of trust in physician on self-efficacy, adherence and diabetes outcomes. Social Science and Medicine, 68, 1060-1068.

Majcen, D., Itard, L., \& Visscher, H. (2013a). Actual and theoretical gas consumption in Dutch dwellings: What causes the differences? Energy Policy, 61, 460-471.

Majcen, D., Itard, L., \& Visscher, H. (2013b). Theoretical vs. actual energy consumption of labelled dwellings in the Netherlands: Discrepancies and policy implications. Energy Policy, 54, 125-136.

Manski, C. (2000). Economic analysis of social interactions. Journal of Economic Perspectives, 14, $115-136$.

Milieu Centraal. (2012). Gemiddeld energiegebruik in huis. http://www.milieucentraal.nl/thema\%27s/ thema-1/energie-besparen/gemiddeld-energiegebruik-in-huis/. Retrieved from June 6, 2012.

Murphy, L., \& Meijer, F. (2011). Waking a sleeping giant: Policy tools to improve the energy performance of the existing housing stock in the Netherlands. In T. Lindström \& L. Nilsson Borg (Eds.), Energy efficiency first: The foundation of a low-carbon society. ECEEE 2011 (pp. 1107-1118). France: Belambra Presqu'île de Giens.

Murphy, L., Meijer, F., \& Visscher, H. (2012). A qualitative evaluation of policy instruments used to improve energy performance of existing private dwellings in the Netherlands. Energy Policy, 45, 459-468.

Nolan, J., Schultz, W., Cialdini, R., Goldstein, N., \& Griskevicius, V. (2008). Normative social influence is underdetected. Personality and Social Psychology Bulletin, 34, 913-923.

Radar. (2007). Energielabel. (TV Program, November 26, 2007). http://www.allesgemist.nl/video/Radar/ 45630. Retrieved from July 17, 2012.

Radar. (2008). Energielabel. (TV Program, February 18, 2008). http://www.trosradar.nl/uitzending/item/ 1189/energielabel/. Retrieved from July 17, 2012.

Rijksoverheid. (2015). Energielabel woningen (en gebouwen). https://www.rijksoverheid.nl/onderwerpen/ energielabel-woningen-en-gebouwen. Retrieved from September 23, 2015.

Rowe, R., Schulze, W., \& Breffle, W. (1996). A test for payment card biases. Journal of Environment Economics and Management, 31, 178-185.

Schultz, W. (2001). The structure of environmental concern: Concern for self, other people, and the biosphere. Journal of Environmental Psychology, 21, 327-339.

Schultz, W., \& Zelezny, L. (2003). Reframing environmental messages to be congruent with American values. Human Ecology Review, 10, 126-136.

Steg, L. (2008). Promoting household energy conservation. Energy Policy, 36, 4449-4463.

Steg, L., \& Vlek, C. (2009). Encouraging pro-environmental behaviour: An integrative review and research agenda. Journal of Environmental Psychology, 29, 309-317. 
Stern, P. (2000). Toward a coherent theory of environmentally significant behavior. Journal of Social Issues, 56, 242-407.

Stern, P., Aronson, E., Darley, J., Kempton, W., Hill, D., Hirst, E., \& Wilbanks, T. (1987). Answering behavioral questions about energy efficiency in buildings. Energy, 12, 339-353.

Sütterlin, B., Brunner, T., \& Siegrist, M. (2011). Who puts the most energy into energy conservation? A segmentation of energy consumers base on energy-related behavioral characteristics. Energy Policy, 39, 8137-8152.

Tangari, A., \& Smith, R. (2012). How the temporal framing of energy savings influences consumer product evaluations and choice. Psychology and Marketing, 29, 198-208.

Truffer, B., Markard, J., \& Wüstenhagen, W. (2001). Eco-labeling of electricity- strategies and tradeoffs in the definition of environmental standards. Energy Policy, 29, 885-897. 